\title{
The Guidelines of Product Design from the Vetivers Grass Fiber Innovation (Case Study of the Handicraft Product Group, Phayao Province)
}

\author{
Rosjana Chandhasa ${ }^{1}$ Jong Boonpracha ${ }^{1}$ Somsakul Jerasilp ${ }^{1}$ Palang Wongtanasuporn ${ }^{1}$ \\ Faculty of Industrial Technology, Department of Industrial Design, SuanSunandhaRajabhat University, Thailand \\ Correspondence: RosjanaChandhasa. Tel: 66-955-181-285. E-mail: rosjana.ch@ ssru.ac.th
}

Received: September 6, 2017

Accepted: October 16, 2017 Online Published: November 28, 2017

doi:10.5539/ass.v13n12p77

URL: https://doi.org/10.5539/ass.v13n12p77

\begin{abstract}
This research aims to study the process and the physical property of the vitiate grass fiber by spinning vetiver grass with other natural fibers such as cotton, SamiaRicini, silk and plastic fiber such as plastic rope, wire rope and straw rope. The exploration was conducted by Ban KoSoa women group cooperative settlement, Ban Kae Mai handicraft product group and Ban Don Chai handicraft product group in Pusang District, Phayao Province. The physical properties examination, namely: ASTMD 1059:2001 Standard Test Method for Fiber Size, ASTM D 2256: 2002 Standard Test Method for Fiber Toughness with Hardness and Flexibility fiber Equipment, the results of examination would be brought to determinate for the handicraft product development design. The results from this exploration revealed that the fiber size was $0.73-0.15 \mathrm{Ne}$, the tenacity (toughness) as maximum tensile strength was $4.75-9.97 \mathrm{kgf}$ and the elongation at break was 7.73-11.48 percentages. The vetiver grass fiber mixed with straw rope had the tenacity as maximum tensile strength with differently at the statistically significant level of .05 , the tenacity as maximum tensile strength average at $9.9 \mathrm{kgf}$, the vetiver grass fiber mixed with cotton fiber had the tenacity as maximum tensile strength with differently at the statistically significant level of .05 , the tenacity as maximum tensile strength average at $6.60 \mathrm{kgf}$. The vetiver grass fiber mixed with wire rope had the highest elongation at break with differently at the statistically significant level of .05 by with the elongation break was 11.48 percentage. The vetiver grass fiber mixed with SamiaRicini fiber had the elongation break point with differently at the statistically significant level at .05 , the elongation at break was 11.6 percentage. According to the handicraft product development guideline from the physical property of the vetiver grass fiber on the basis of this finding, the strength fiber as the vetiver grass fiber mixed with straw rope fiber or cotton fiber could be used for supporting weight product requirement, the elasticity fiber as the vetiver grass fiber mixed with straw rope fiber or SamiaRicini could be used for product which soft and flexibility requirement, the utility from using fiber color that spinning for beauty could be used the vetiver grass fiber that spinning and mixed with other fiber.
\end{abstract}

Keywords: Vetiver grass fiber, Development, Handicraft

\section{Introduction}

Vetiver is a kind of Poaceae family most closely related to corn, sorghum, sugar cane and lemon grass, native to Northern India, Bangladesh, and Burma, according to Land Development Department operating had collected the vetiver grass types in Thailand and also in other countries. The vetiver grass had been selected about 10 types of vetiver grass in domestic and one type from Sri Lanka by Land Development conducting. The vetiver grass has been widely spread about 12 types throughout the globe, 2 types with 10 vetiver grass varieties in Thailand namely, 1) vetiver essential oil or Vetiveriazizanioides $(\mathrm{L})$ Nash with 6 vetiver varieties such as NakhonSawan, Kampangphet1, Loei, Roied and PrachuapKhiri Khan 2) VetiverianemoralisA. Camus with 4 varieties such as Sri Lanka, Kampangphet2, Suratthani and Sonkla (Tassanapilom, S., n.d.) "Vetiver": King Rama IX of Thailand had advocated the idea of vetiver grass studies provided that prevent soil erosion, in addition to conserve soil moisture. The Land Development Department had explored the area and operated for growing vetiver grass, investigated a including other utilities of vetiver grass since 1991 until now. In 1993, the King ordered the all government agencies capability for vetiver propagation collaborate with the Land Development Department so as to produce and apportion the vetiver sprout to the target group sufficiently. The King loyal thought about the vetiver leaf were used as materials that having enough if they had been promoting operation into industrial level. As a result of the vetiver grass has many leaves and a fast growth, therefore the leaves of vetiver should have been studied for other suitable purpose in order that not affected the main purpose which for preventing the soil erosion also help to block the runoff of surface water. Consequently, using the vetiver grass for other relevant purpose should consider about planting area especial in order to having volume enough on demand for producing handicraft products. Phayao province has been the largest vetiver grass planting area in the North of Thailand, the growing of the vetiver grass were investigated and conducted by the Land Development Department, there had been begun the growing experiment as prototype along the mountain at the Land Development Station of province as well as distributed agriculturists the sprouts in the areas for growing in their areas as preventing soil erosion and making planted area for growing vetiver grass, the agriculturists had known the 
vetiver grass benefits as material object (Provincial Community Development office of Phayao Province, 2009). Consequently, the Department of Industrial Promotion Region 1 had managed the handicraft from the vetiver grass training for the villagers in the village, therefore the villagers they form into group which attention as the SatriSahakornNikom (Women Group Cooperative Settlement)had token the harvested vetiver grass to make craft products therefore, this has produced additional income for the villagers until now.

Presently, the vetiver handicraft products development have the guidelines of development such as the form and the figure so as to be suitable usability, processing technique method development, product quality development, and also the vetiver fiber grade development for textile. However, these products were produced by manufacture industry technology thus, most benefits become to the property of capitalists group, unfortunately the villager group which a previously produced the handicraft would lose opportunity. At present time, using eco-friendly and natural material product campaign to resolve global warming effect has been the international emphasizing, obviously at campaign advertising such as stopping using the plastic and replacing with cotton bag, selecting natural materials especial plant fiber material by weaving technique method for various item styles on domestic also international market demand.

From this research investigated, the handicraft production have many processing step technique such as boiling, sun drying, weakening, compressing and spinning, whereas preparing process which had a weak and a limitation for instance, a limitation length of leaf is 80-100 centimeters with too short and a limitation of weaving style, however, if this limitation could be eliminated as well as approving technique method or increasing strength quality, adding technique method to assists the beauty that could be able promote and develop product level bring to international standardization accompany with more various style. For this study, the researcher had investigated materials which were natural fiber from local and availably easy find out in Phayao area consists of cotton fiber, SamiaRicini silk including plastic rope which made from plastic rope synthetic these availably easy to find at local. Researcher realized about the importance and utility from mixing and developing vetiver fiber material could be able strengthen or sticky physical property, longer, able be producing handicrafts with various styles in any handicraft technique method such as weaving, weaving and tying which were increasing the alternative styles, adding value and worth for vetiver grass handicraft products

\section{Research Objectives}

To analyze the properties testing of the vetiver grass fiber that are size of fiber, the tenacity of fiber and the elasticity of fiber mixed with the natural fibers such as the cotton fiber, the SamiaRicini fiber and the silk fiber and the vetiver grass fiber mixed the plastic fiber such as the plastic rope fiber, the wire rope fiber and the straw rope fiber conduce to the handicraft product development guidelines.

\section{Research Methodology}

This research is the experimental method by collecting data from the vetiver grass fiber sampling with the physical properties testing, the results of examination were used to analysis data by statistical technique, in sequence at follows 1) studying the literature review and the research with concern the vetiver grass fiber development as well as the physical properties of fibers 2) examination of the vetiver fiber mixed other material fibers as the natural fibers such as the cotton fiber, the SamiaRicini fiber and the silk fiber as well as the plastic fibers such as the plastic rope fiber, the wire rope fiber and the straw rope fiber and 3) studying of the vetiver grass fiber physical properties testing in terms of the strength of fiber, the size of fiber and the elasticity of fiber for selecting a suitable properties usage to create the handicraft products.

\subsection{Scope of research}

The delimitation of the study included:

Stage 1: Area scope and sampling of studying the vetiver grass fiber materials with planting and spinning was in Phayao province.

Stage2: Process scope and procedure processing of the vetiver grass by studying 3 groups of the vetiver handicraft producers, namely; Ban KoSoa group cooperative settlement, Ban Kae Mai handicraft product group and Ban Don Chai handicraft product group in Pusang District, Phayao Province. The experiment was conducted by processing of the vetiver grass mixed with the natural fibers and the plastic fibers with easily find out at the local area, the spinning vetiver grass mixed with other materials were examined the physical properties by measuring the fiber size, the fiber strength and the fiber elasticity in order to analyze the physical properties of vetiver grass fiber types.

Stage 3: Scope of population and sampling in this experiment, the spinning vetiver grass fiber mixed with 3 natural fibers namely: the cotton fiber, the SamiaRicini fiber and the silk fiber, the plastic fibers namely: the plastic rope fiber, the wire rope fiber and the straw rope fiber. The variables of this study

1. Independent variables, namely: the spinning vetiver grass fiber mixed with the natural fibers and the plastic fibers

2. Dependent variables, namely: fiber size, fiber tenacity and fiber elasticity.

\subsection{Research instruments}

Stage 1: The vetiver grass fiber was span and braid into strand as 2, 3 and 4 millimeters, with each strand 30 meters for physical properties examination consist of the size of fiber, the strength of fiber and the elasticity of fiber. 
Stage2: The spinning vetiver grass fiber mixed with the natural fiber such as the cotton fiber, the SamiaRicini fiber and the silk fiber with the ratio leaves of vetiver grass 2 parts per the natural fiber 1 part that make 3 strands with the size as 2, 3 and 4 millimeters with each strand 30 meters

Stage3: The spinning vetiver grass mixed with the plastic fiber such as the plastic rope fiber, the wire rope fiber and the straw rope fiber with the ratio leaves of vetiver grass 2 parts per the plastic fiber 1 part that make the strands as 2,3 and 4 millimeters with each strand 30 meters

Stage4: The equipment for fiber strength testing is TENSILE TESTING MACHINE (INSTRON MODEL 5566) of Textile Testing Center, Thailand Textile Institute.

\subsection{Data collection}

Using the spinning vetiver grass fiber and braids within 2, 3 and 4 millimeters, cut if for each strand about 250 millimeters to 10 strands per each size, ASTM D 1059:2001 Standard Test Method for Fiber Size, ASTM D 2256: 2002 Standard Test Method for Fiber Toughness with Hardness and Flexibility fiber by TENSILE TESTING MACHINE (INSTRON MODEL 5566), the elasticity fiber testing with the speed ratio testing 300 millimeters per minute, in the time of testing 250 millimeters, moisture condition testing at $21 \pm^{0} \mathrm{C}$, relative humanity at $65 \pm 2$ percentages and the elongation at break measurement .

\subsection{Data analysis}

Data analysis on the basic processing of preparing, processing, review literature and data analysis from the physical properties testing such as fiber strength, fiber proportion and fiber elongation. The statistics used for data analysis is mean, percentage, standard deviation and one way analysis of variance (One-Way ANOVA)

\section{Data Analysis Results}

Researcher divided research results into 4 parts consisted of 1) the physical characteristic data of vetiver grass result 2) the process and procedure of vetiver grass processing result 3) data analysis result of the vetiver grass fiber mixed with other material fibers and 4) the handicraft product development guideline result, as follows:

\subsection{The physical characteristics data of the vetiver grass result}

Researcher revealed that the vetiver essential oil or Vetiveriazizanioidesin which Sri Lanka type is the most cultivated and commonly find out in Phayao Province that is appropriate and favorable to create the vetiver grass handicraft product because it is a chump, blade is long and wider than VetiverianemoralisA A. Camus, totally dark green leaf and coating with less wax that affect to coarse and not shiny. The time of harvesting of the vetiver grass would be cutting for work in 45-60 days during a rainy season, however, the vetiver grass should not harvest outside the rainy season owing to the vetiver grass leaves will be hard, lean and easily brittle that affect to create product should be not beautiful, as shown in Table 1

Table1.Comparative of the physical characteristic between Vetiveriazizanioides and Vetiverianemoralis

\begin{tabular}{|c|c|c|}
\hline \multirow[t]{2}{*}{ Origin } & Vetiveriazizanioides & Vetiverianemoralis \\
\hline & $\begin{array}{l}\text { - In the middle of Asia which assumes as in } \\
\text { India. } \\
\text { - } \quad \text { It has grown and propagation with commonly }\end{array}$ & $\begin{array}{l}\text { - In the South East of Thailand, Lao, Cambodia and Vietnam. } \\
\text { - It can spread propagation in a natural environment with limit } \\
\text { water condition }\end{array}$ \\
\hline Bunchgrass & $\begin{array}{l}\text { - Having clumps with each blade is long and a } \\
\text { high parallel } \\
\text { - Height of } 150-200 \mathrm{~cm} \text {. } \\
\text { - The top of the apex and the culm could be } \\
\text { separate into a small piece. }\end{array}$ & $\begin{array}{l}\text { - Having a clumps with each blade is long, spread out and bend } \\
\text { down like bunch but it not a high parallel like aroma vetiver grass. } \\
\text { - Heightof } 100-150 \mathrm{~cm} \text {. } \\
\text { - Neither the top of apex nor the culm could not separate into a small } \\
\text { piece. }\end{array}$ \\
\hline Leaf & $\begin{array}{l}\text { - } 45-100 \mathrm{~cm} \text {. long, } 0.6-1.2 \mathrm{~cm} \text {. wide } \\
\text { - A dark green color, totally green at the } \\
\text { backside, approximate white at the inside, having } \\
\text { the fibrous lines at the surface area when seeing at } \\
\text { the sunlight } \\
\text { - Having slightly waxy coating was that affect to } \\
\text { soft and greasy leaf, at the surface leaf look like a } \\
\text { sponge. }\end{array}$ & $\begin{array}{l}\text { - } 35-80 \mathrm{~cm} \text {. long, } 0.4-0.8 \mathrm{~cm} \text {. wide. } \\
\text { - A pale green color, the backside was fold as triangle, the inside } \\
\text { has the same color as the backside but more pale than total leaf, } \\
\text { when seeing at the sunlight could not see the fibrous lines at the } \\
\text { surface area. } \\
\text { - A rough leaf, having a few waxy coating affect to the leaf is not } \\
\text { shiny. }\end{array}$ \\
\hline $\begin{array}{l}\text { Fluorescence } \\
\text { and flower }\end{array}$ & $\begin{array}{l}\text { - } \quad \text { The panicle ishigh at } 150-250 \mathrm{~cm} . \\
\text { - } \quad \text { Mostly, approximate purple. } \\
\text { - } \quad \text { A flower have not the appendage. }\end{array}$ & $\begin{array}{l}\text { - The panicles ishigh at } 1-00150 \mathrm{~cm} \text {. } \\
\text { - Various colors consisted of a white cream to a purple color. } \\
\text { - A flower have the appendage }\end{array}$ \\
\hline Seed & -A seed is a bigger than Vetiveria nemoralis & -A seed is a smaller than Vetiveria zizanioides. \\
\hline
\end{tabular}

4.2 The process and procedure of vetiver grass processing result

Researcher using the vetiver essential oil which Sri Lanka type as the type that the producers had been cultivating in the area of Phayao Province and using for the various vetiver grass handicraft, the processing procedure as the follows, 
1) Preparing of the vetiver grass fiber by using the vetiver grass after 1 year of planting, the time of harvesting the vetiver leaves should be during a rainy season within 45-60 days owing to getting the leaf about 80-120 centimeters long, the leaf cutting at the bottom of stem by measuring from the stem about 20 centimeter, boil the leaves in the boiling water for 20 minutes continually, sun drying for 1-2 days until it dry depend on the intense sunlight and the leaf was were weaken as the straight line with 2-3 millimeter in order to make an equal straight line, from the following in Figure 1.

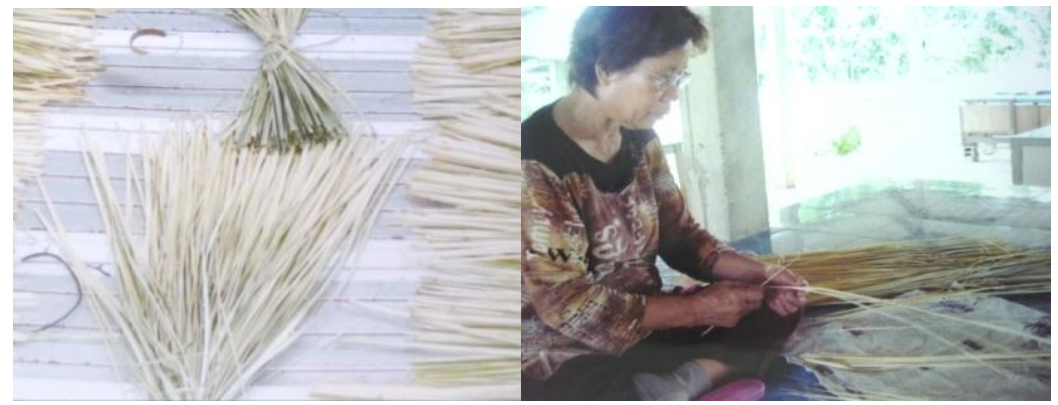

Figure1. The vetiver grass drying and weakening from: Chandhasa, R. (2011).

Bringing the vetiver grass leaf with 80-120 centimeters had been span and braided as the strand owing to make the strong fiber that could be supporting a heavy product, therefore it was a suitability for supporting a heavy product. Beside the vetiver grass with soft, flexibility or emphasizing of beautiful color, that could be mixed with other fibers such as cotton fiber, SamiaRicini fiber, silk fiber, plastic rope, wire rope and straw rope, as showing at Figure 2-3

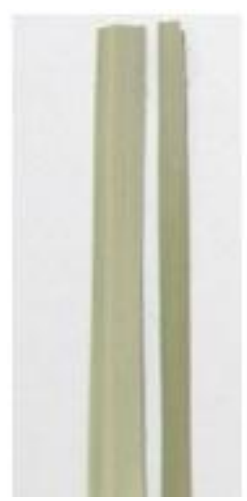

Vetiver leaves
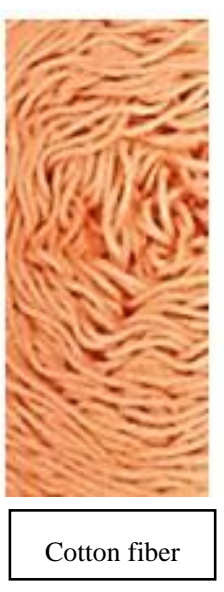
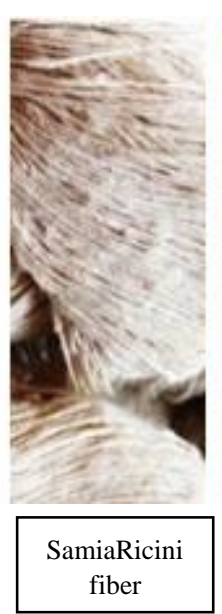
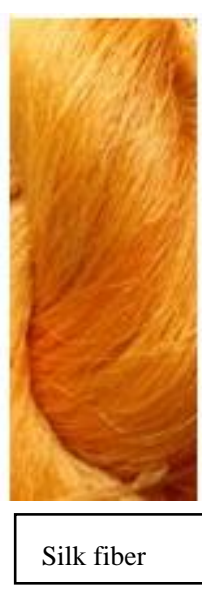

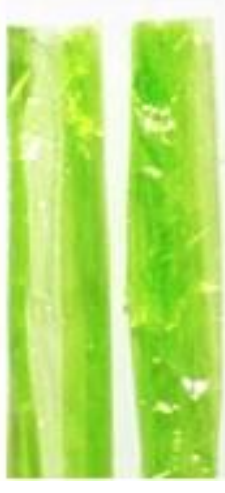

Plastic rope
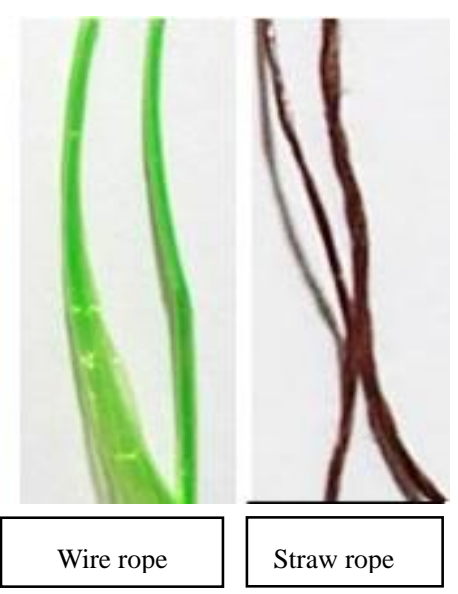

Figure 2. The spinning and braiding the vetiver grass fiber mixed with other fiber From: Chandhasa, R., 2014

\subsection{The result of the vetiver grass fiber mixed with other material}

The physical properties of the spinning vetiver grass fiber mixed with the natural fibers and the plastic fibers, totally 7 fibers, the results shown at table $2-4$

Table 2.The physical properties of the fibers $(\mathrm{N}=30)$

\begin{tabular}{|c|c|c|c|c|c|c|c|c|}
\hline \multirow[t]{2}{*}{ The Physical properties fibers } & \multicolumn{4}{|c|}{$\begin{array}{l}\text { Port portion } \\
\qquad(\mathrm{Ne})\end{array}$} & \multicolumn{2}{|c|}{$\begin{array}{l}\text { Maximum tensile } \\
\text { strength (Kg.force) }\end{array}$} & \multicolumn{2}{|c|}{$\begin{array}{c}\text { Elongation at break } \\
\text { (Percentages) }\end{array}$} \\
\hline & Min & Max & $\overline{\bar{x}}$ & SD. & $\bar{x}$ & SD. & $\bar{x}$ & SD. \\
\hline The vetiver grass fiber & 0.73 & 0.31 & 0.48 & 0.22 & 5.89 & 2.36 & 7.73 & 1.69 \\
\hline The vetiver fiber mixed with cotton fiber & 0.52 & 0.25 & 0.37 & 0.14 & 6. $06^{*}$ & 1.66 & 9.67 & 1.42 \\
\hline The vetiver fiber mixed with SamiaRicinifiber & 0.55 & 0.25 & 0.37 & 0.14 & 5.44 & 1.20 & $11.09 *$ & 3.99 \\
\hline The vetiver fiber mixed with the silk fiber & 0.55 & 0.28 & 0.42 & 0.14 & 5.35 & 0.97 & 7.89 & 1.03 \\
\hline The vetiver fiber mixed with plastic rope fiber & 0.71 & 0.39 & 0.55 & 0.16 & 4.75 & 1.68 & 9.95 & 2.26 \\
\hline The vetiver fiber mixed with wire rope fiber & 0.66 & 0.28 & 0.50 & 0.20 & $9.97 * *$ & 3.88 & $11.48 * *$ & 2.85 \\
\hline The vetiver fiber mixed with straw rope fiber & 0.47 & 0.15 & 0.29 & 0.16 & 7. 89 & 0.73 & 11.16 & 1.43 \\
\hline
\end{tabular}

* The vetiver fiber mixed with the natural fibers had the highest average

** The vetiver fiber mixed with the plastic fibers had the lowest average 


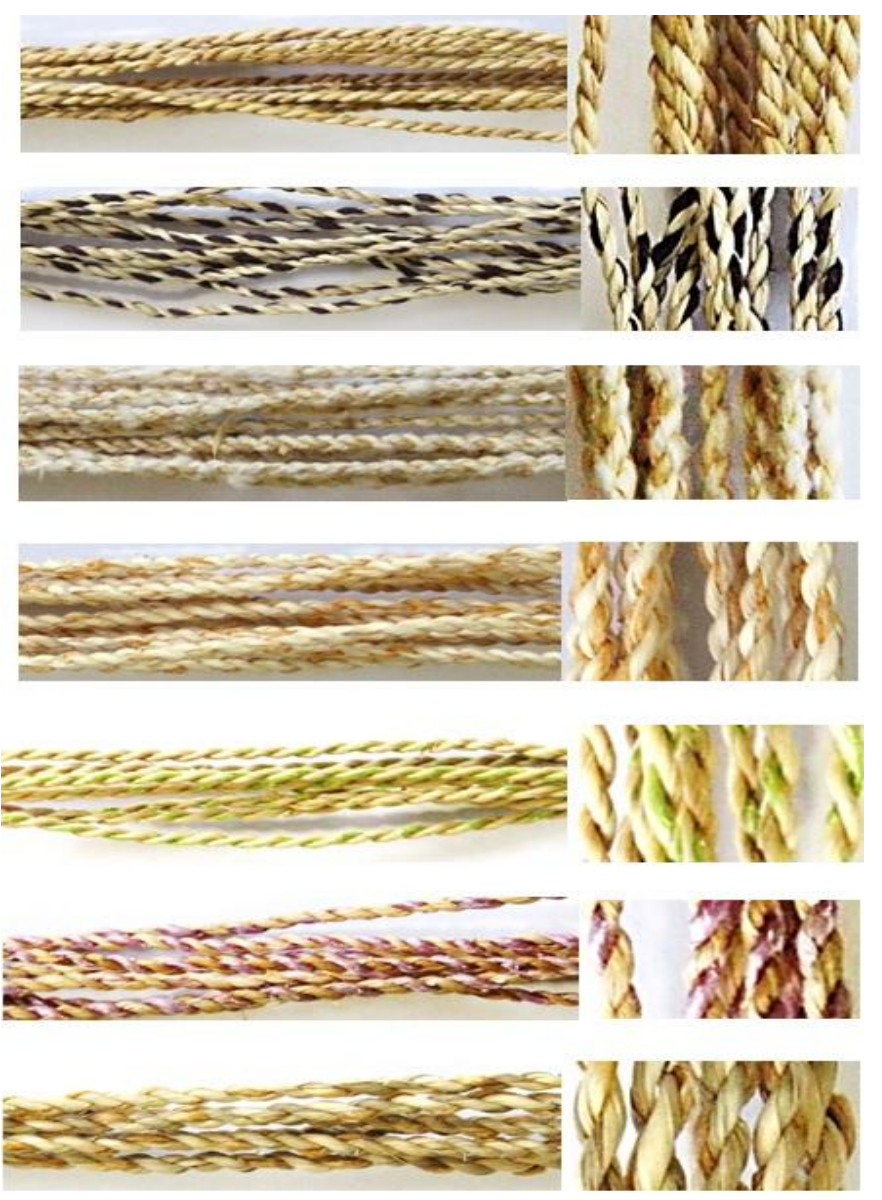

A total Vetiver fiber

The spinning vetiver fiber mixed with the cotton fiber

The spinning vetiver grass fiber mixed with the SamiaRicini fiber

The spinning vetiver grass fiber mixed with the silk fiber

The spinning vetiver grass fiber mixed with the plastic rope fiber

The spinning vetiver grass fiber mixed with the wire rope fiber

The spinning vetiver grass fiber mixed with the straw rope fiber

Figure 3. The spinning and braiding the vetiver grass fiber mixed with other tiber From: Chandhasa, R., 2014

As shown from table 2, the spinning vetiver grass were examined the physical properties of the proportion fiber overall was with range $0.73-0.15 \mathrm{Ne}$, the tenacity (tensile strength) was with range 4.75-9.97 kilogram force and the elongation at break point was with range 7.73-11.48 percentages which is explained as the follows; The spinning vetiver grass fiber mixed with the plastic fiber which the highest tenacity level was the spinning vetiver grass fiber mixed with the wire rope fiber by means of the maximum tensile strength of the spinning grass fiber mixed with the wire rope fiber with the average was 9.97 kilogram force with the average, the standard derivation was 3.88 , as the follows, the spinning vetiver grass mixed with the straw rope fiber, having the maximum tensile strength with the average was 7.89 kilogram force, the standard derivation was 0.73 and the spinning vetiver grass fiber mixed with the plastic rope, having the maximum tensile strength with the average was 4.75 kilogram force and the standard derivation was 1.68 , respectively. The elongation at break of the spinning vetiver grass fiber mixed the plastic fiber which the highest level was the spinning vetiver grass fiber mixed with the wire rope fiber by means of the elongation at break of the spinning vetiver grass fiber mixed with the wire rope fiber was the 11.48 percentages, the standard derivation was 2.85 , at the follows the spinning vetiver grass fiber mixed with the straw rope fiber, having the elongation at break was 11.16 percentages, the standard derivation was 1.43 and the spinning vetiver grass fiber mixed with the straw rope fiber, having the elongation at break was 9.95 percentages and the standard derivation was 2.26 , respectively.

The spinning vetiver grass fiber mixed with the natural fiber which the highest tenacity level was the spinning vetiver grass fiber mixed with the cotton fiber by means of the maximum tensile strength of the spinning grass fiber mixed with the cotton fiber with the average was 6.06 kilogram force, the standard derivation was 1.66, as the follows, the vetiver grass fiber, having the maximum tensile strength with the average was 5.89 kilogram force, the standard derivation was 2.36 and the spinning vetiver grass fiber mixed with the SamiaRicini fiber, having the maximum tensile strength with the average was 5.44 kilogram force and the standard derivation was 1.20 , respectively The elongation at the break point of the spinning vetiver grass fiber mixed the natural fiber which the highest level was the spinning vetiver grass fiber mixed with the SamiaRicini fiber by means of the elongation at break of the spinning vetiver grass fiber mixed with the SamiaRicini fiber, was the 11.06 percentages, the standard derivation was 3.99, at the follows the spinning vetiver grass fiber mixed with the cotton fiber, having the elongation at break was 9.67 percentages, the 
standard derivation was 1.42 and the spinning vetiver grass fiber mixed with the silk fiber, having the elongation at break point was 7.89 percentages and the standard derivation was 1.03 , respectively.

As shown form table 3 when compared the maximum tensile strength of fiber testing for difference between means from two separate revealed the vetiver grass fiber types had the maximum tensile strength with differently at the statistically significant level of .05 that was: The spinning vetiver grass fiber mixed with the cotton was a statistically significant level at .05 difference in terms of the maximum tensile strength among of the spinning vetiver grass fiber mixed with the wire rope fiber and the spinning vetiver grass fiber mixed with the wire rope fiber, while the vetiver grass fiber was no statistically significant difference in terms of the maximum tensile strength among of the spinning vetiver grass fiber mixed with the SamiaRicini fiber and the spinning vetiver grass fiber mixed with the silk fiber. Furthermore, there was a statistically significant level at .05 differences in terms of the maximum tensile strength between the spinning vetiver grass fiber mixed with the wire rope fiber and other fibers

Table 3.The difference between means testing of the tensile strength of fibers

\begin{tabular}{|c|c|c|c|c|c|c|c|c|c|}
\hline \multirow{2}{*}{\multicolumn{2}{|c|}{ Lists of fibers }} & \multirow{3}{*}{$\begin{array}{l}\text { Mean } \\
5.89\end{array}$} & \multicolumn{7}{|c|}{ Type of fibers } \\
\hline & & & \multirow[t]{2}{*}{1} & \multirow{2}{*}{$\begin{array}{l}2 \\
762 .\end{array}$} & \multirow{2}{*}{$\begin{array}{l}3 \\
385 .\end{array}$} & \multirow{2}{*}{$\begin{array}{l}4 \\
299 .\end{array}$} & \multirow{2}{*}{$\begin{array}{l}5 \\
032 . *\end{array}$} & \multirow{2}{*}{$\begin{array}{l}6 \\
.000^{*}\end{array}$} & \multirow{2}{*}{$\begin{array}{l}7 \\
.000^{*}\end{array}$} \\
\hline 1 & The vetiver grass fiber & & & & & & & & \\
\hline 2 & The vetiver mixed with the cotton fiber & 6.06 & & & .242 & .180 & $.015^{*}$ & $.000^{*}$ & $.001 *$ \\
\hline 3 & The vetiver fiber mixed with SamiaRicinifiber & 5.44 & & & & .864 & .199 & $.000 *$ & $.000 *$ \\
\hline 4 & The vetiver mixed with the silk fiber & 5.35 & & & & & .266 & $.000 *$ & $.000 *$ \\
\hline 5 & The vetiver mixed with the plastic rope fiber & 4.75 & & & & & & $.000 *$ & $.000 *$ \\
\hline 6 & The vetiver mixed with the wire rope fiber & 9.97 & & & & & & & $.000 *$ \\
\hline 7 & The vetiver mixed with the straw fiber & 7.89 & & & & & & & \\
\hline
\end{tabular}

* Differently at the statistically significant level at .05

Table 4.The difference between percentages testing of the elongation at break of fibers

\begin{tabular}{|c|c|c|c|c|c|c|c|c|c|}
\hline \multirow{2}{*}{\multicolumn{2}{|c|}{ Lists of the fibers }} & \multirow{3}{*}{\begin{tabular}{|l} 
Mean \\
7.73
\end{tabular}} & \multicolumn{7}{|c|}{ Type of fibers } \\
\hline & & & & \multirow{2}{*}{$\begin{array}{l}2 \\
.001^{*}\end{array}$} & \multirow{2}{*}{$\begin{array}{l}3 \\
.000 *\end{array}$} & \multirow{2}{*}{$\begin{array}{l}4 \\
.797\end{array}$} & \multirow{2}{*}{$\begin{array}{l}5 \\
.000 *\end{array}$} & \multirow{2}{*}{$\begin{array}{l}6 \\
.000 *\end{array}$} & \multirow{2}{*}{$\begin{array}{l}7 \\
.000^{*}\end{array}$} \\
\hline 1 & The vetiver grass fiber & & & & & & & & \\
\hline 2 & The vetiver mixed with the cotton fiber & 9.67 & & & $.018 *$ & $.003 *$ & .629 & $.003^{*}$ & $.013^{*}$ \\
\hline 3 & The vetiver fiber mixed with SamiaRicinifiber & 11.09 & & & & $.000 *$ & .058 & .515 & .904 \\
\hline 4 & The vetiver mixed with the silk fiber & 7.89 & & & & & $.001 *$ & $.000 *$ & $.000^{*}$ \\
\hline 5 & The vetiver mixed with the plastic rope fiber & 9.95 & & & & & & $.011^{*}$ & $.044^{*}$ \\
\hline 6 & The vetiver mixed with the wire rope fiber & 11.48 & & & & & & & .569 \\
\hline 7 & The vetiver mixed with the straw fiber & 11.16 & & & & & & & \\
\hline
\end{tabular}

* Differently at the statistically significant level at .05

As shown form table 4 when compared the elongation at break percentages of fibers testing for difference between means from two separate revealed the vetiver grass fiber types had the elongation at break percentages with differently at the statistically significant level of .05 , the result was: The spinning vetiver grass fiber mixed with the SamiaRicini fiber was a statistically significant level at .05 difference in terms of the elongation at break percentages among of the vetiver grass fiber, the spinning vetiver grass fiber mixed with the cotton fiber and the vetiver grass fiber mixed the silk fiber, beside the spinning vetiver grass fiber mixed with the SamiaRicini fiber was no statistically significant difference in terms of the elongation at break among of the spinning vetiver grass fiber mixed with the plastic rope fiber, the spinning vetiver grass fiber mixed with the wire rope fiber and the spinning vetiver grass fiber mixed with the straw rope fiber. Moreover, the spinning vetiver grass fiber mixed with the wire rope fiber was a statistically significant level at .05 difference in terms of the elongation at break percentages among of the spinning vetiver grass fiber mixed with the plastic rope fiber, the spinning vetiver grass fiber mixed with the cotton fiber and the spinning vetiver grass fiber mixed with the silk fiber, beside the spinning vetiver grass fiber mixed with the wire rope fiber was no statistically significant difference in terms of the elongation at break among of the spinning vetiver grass fiber mixed with the SamiaRicini fiber and the spinning vetiver grass fiber mixed with the straw rope fiber.

\subsection{The handicraft product development guideline analysis result}

The handicraft product development guideline analysis from the exploration physical properties, the results revealed that bringing the vetiver grass fiber was span and braid and mixed with the natural fibers and the plastic fibers which affected to differential properties in terms of durable strength for pulling strength and flexibility. Consequently, researchers have selected from the fiber properties for 3 guidelines of the handicraft product development, as follows:

Approach 1: Using the strongest fiber for creating a big bag product with could be used for supporting a heavy product that is the vetiver grass fiber mixed with the wire rope fiber which could be supporting the weight with the average at 9.97 kilogram force as well as having the most elasticity is shown in Figure 4. 


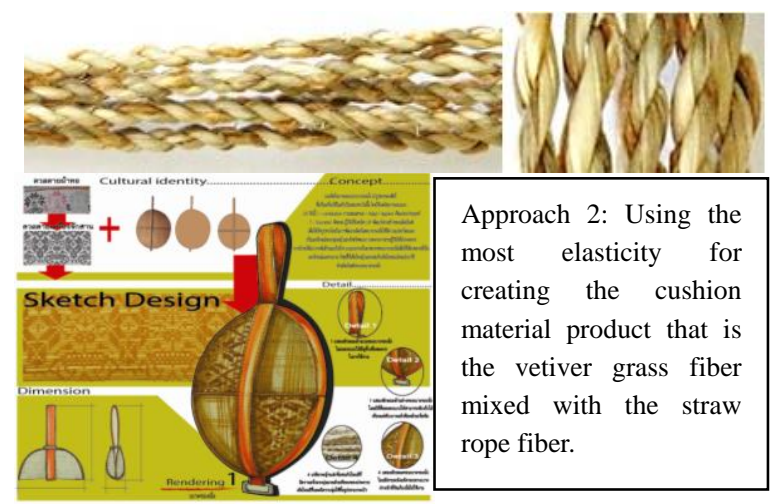

Figure4. The applying the fiber usage to a bag productfrom: Chandhasa, R. 2014

Approach 2: Using the most elasticity for creating the pillow product or the cushion material that are the vetiver grass fiber mixed with the wire rope fiber, the vetiver grass fiber mixed with the SamiaRicini fiber and the vetiver grass fiber mixed with the straw rope fiber, as shown in picture 5 and Figure 6.

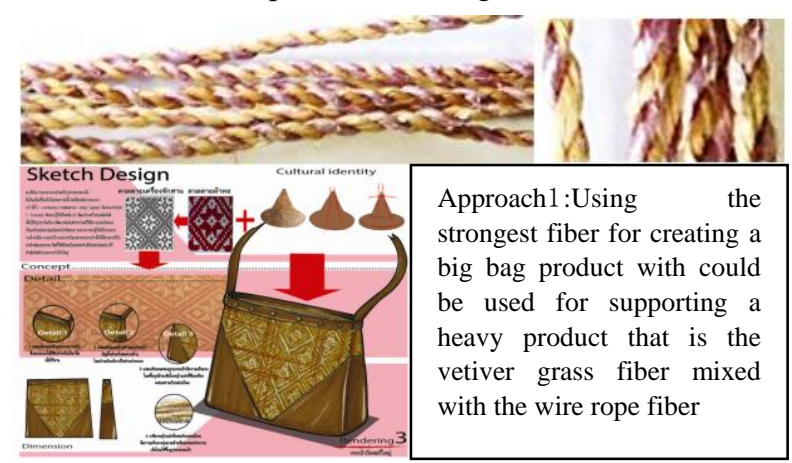

Figure5. The applying the fiber usage to a seat cushion productfrom: Chandhasa, R. 2014

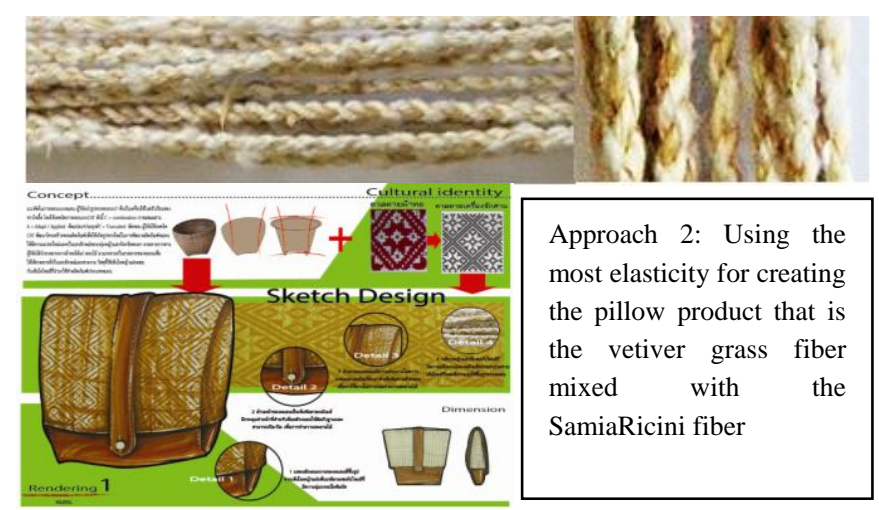

Figure6. The applying the fiber usage to the pillow productFrom: Chandhasa, R. 2014.

Approach 3: Using the vetiver grass mixed with the silk fiber for the clutch bag product, as shown in Figure 7

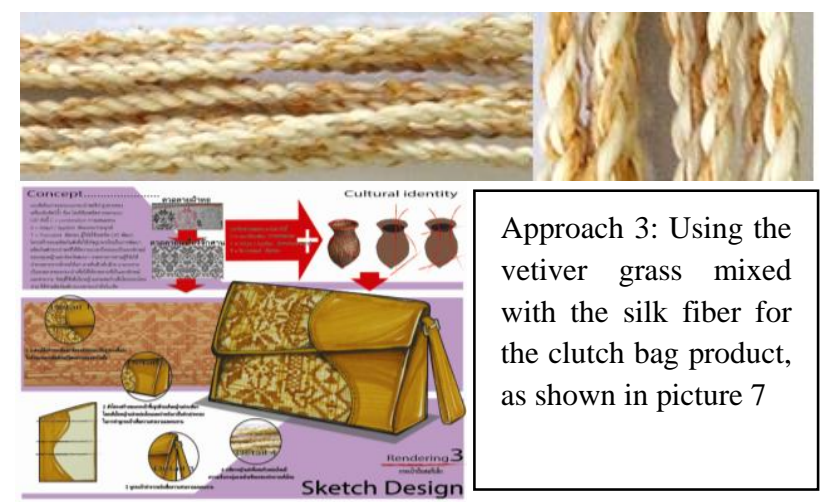

Figure 7. Applying the vetiver grass fiber usage to the clutch from: Chandhasa, R. 2014. 


\section{Conclusion and Discussion}

The conclusion of this research revealed the aroma vetiver grass which Srilanga line had obviously suitable properties for creation handicraft product owning to having a long of leaf with 80-120 centimeters, soft and shiny leaf, bring the leaf for using should have cut leaf apex about 20 centimeters because it had some small sharp thorns, the aims of boiling the leaves in boiled water mixed with some salts continually in 15-20 minutes for making vetiver grass leaves with soft, sticky and more white, rinse with 1 time as well as drying at the air for 1-2 days so as to be hardly moldy, the aims of weakening vetiver grass to make a straight line with equally and the span leaves of vetiver were braids on specific proportion

The physical properties results had been explored, span braids vetiver fiber proportion had been measured about .73-0.15 Ne with standardized tread with various proportions due to spinning braids vetiver grass leaves process which using 3-5 vetiver grass lines and specifying physical measurement by craftsmen could not control the rotation force of spinning of each craftsmen therefore to the vetiver grass fibers had difference proportion, consequently they also had difference tightness and strength.

The spinning vetiver grass fiber mixed with the natural fibers had a highest tensile strength with range 5.35-6.06 kilograms force, spinning vetiver grass fiber mixed with the plastic fibers had a tensile strength with range 4.75-9.97 kilograms force, as a results of mixing the spinning vetiver grass fiber together with the plastic fibers could be able increasing tensile strength more than a pure vetiver grass fiber and mixed with the natural fibers, besides the spinning vetiver grass fiber mixed with a clear plastic rope had a lowest tensile strength because it was gauzy and the smallest size with average $0.55 \mathrm{Ne}$ (Total weight [g] x 1,000/ Total length [m.]). For applying research results, being selective fiber type by consideration the physical properties in terms of strength, in terms of elongation as for handicraft products that could be supporting a heavy weight product or soft texture or using the colors from mixed fibers for beauty. For selecting the vetiver grass fibers from each properties, researcher had indicated 3 guidelines of vetiver grass handicraft product that were

1. Strength fiber could be used for supporting a heavy product such as a big bag, a seat cushion made from the vetiver grass fibers that could be more support a heavy product, which could be using the vetiver grass fiber mixed with a wire rope fiber or straw rope fiber.

2. Using of elongation fiber could be used for requirement product of softness and elasticity likes pillow or cushion material that could be using the vetiver grass fiber mixed with wire rope fiber, SamiaRicini fiber or straw rope fiber.

3. The usefulness from the colors of mixed fiber for beauty could be able used the spinning vetiver grass fiber mixed with all other materials to create various handicraft products or product which not consideration for weight supporting due to having colorful colors, the vetiver grass fiber mixed with silk fiber could be able used as the small hardbacks or accessory items, as the silk fiber could express valuable feeling with the own material with related to Chomchalow, N. (2011), had said the vetiver grass had been an excellent material for handicraft due to the fiber form vetiver grass had been adhesive and durable thus it was suitable for handiwork. A campaign of expanding of the vetiver grass planting area for supporting the directly also indirectly usefulness of vetiver grass, the aforementioned also involved with Booth, D. \& Nengah, A.A. (2003), had said the studying of the vetiver grass had been a part of school course and recommended the community had to knowledge about the vetiver grass also the promotion of the vetiver grass benefits in the local media as well as many usefulness to use the vetiver grass on other ways such as for roofing and handicraft

Likewise, this research also related with Jongchansittho, P. (2014:2) had said, the handicraft emphasized to make by hand and to use local materials which was a valuable in both beauty and utility, it had a different pattern in each local area; in addition, it must take the afford to create that works, besides it could explain a local people lifestyle in each place, the handicraft could be classified by the characteristics such as categorized by material used: wooden craft, metal craft, categorized by production process: weaving and entwine and categorized by physical style: textile and pottery. These work creations were built and appear by people that call "handicraftsmen", having knowledge and skills which were descended from ancestor and pass on the knowledge to next generation to subsequent so that the knowledge was lived on, there by the native handicraft had been admired as the "creator" and "preceptor" concurrently. In addition, the vetiver grass fiber mixed with other materials process for product creation could be adjusted with suitable size for product, possibly, the spinning vetiver grass fiber mixed with the other fibers could be brought to braid weaving or Macramé knotting technique which has a professional production and materials selection for the handicraft product, which related to Janatam, J., \& Sikka, P. (2012:103) the research result revealed that the property of the most natural fibers is breakable if they are folded or bend, therefore fiber processing by weaving and spinning as a strand or braid in order to production forming due to the strand was made by braiding and spinning could be more consistence and could be formed easily in addition a beautiful product also related to Laowattanaphong, S. \& Smanchat, S. (2012: 231) exhibited the research results of spinning fiber from the genus Musa and a natural fiber form hemp with spinning strand having the highest level of strength at 678.71 Newton which was used as material in furniture manufacturing by using a weave pattern from the wickerwork that presented the beautiful merging of two materials as well as increasing a strength into material for using in other product that could be able supporting weight effectively. In accordance with Soodsang, N. (2016: 179).concepts gained from this research can be applied to wood and can be used for larger composition and dimension, more natural, increased natural adaptive technologies, mirroring the world in need of 
sustainment and relaxation from chaos. However, furniture design work should also reflect the special need of elderly people such as for the floor, rounded table corners, strong sofas, and light-weight furniture in moderate size to be movable by the elderly people themselves, independent of others. The growth of the furniture and accessories market also depends on other factors such as investment on various projects by the government sector, the government's policy to increase economic activity, the trust of the private sector of the government policy, real estate, condominium and townhome projects being launched, all are key elements in the development of different types of furniture designs.

\section{Suggestion}

1) The experts on fiber had recommended about the vetiver grass fiber selection should select the spinning vetiver grass fiber mixed with cotton fiber, SamiaRicini fiber and silk fiber because they are a natural fiber, having a same property, especially they could be still having a beauty to fiber more than the synthetic fiber

2) Interm of the planting vetiver grass promotion in order that use into handicraft should be studying about the vetiver grass leaves quantity that having enough for product demand, if the quality of vetiver grass leaves are not sufficient, the growing more vetiver grass campaign should be promoted to respond the demand in further development.

3) In term of using the vetiver grass fiber into textile industrial development, the research result of vetiver grass fiber indicates that the vetiver grass fiber characteristics, such as the fineness, tenacity and elongation are similar to plant fiber that used in fabric weaving. Therefore, the studying of leaf fiber mixed with other plant fibers should be experimental which could be able reeling as a tread and bringing it into fabric weaving owning to a new fabric development of textile industry.

4) In term of the process of vetiver grass processing in textile industry should be studying the production in the industry in order to create a new material into producing fabric, further develop to home decoration items and apparel products.

\section{Acknowledgments}

This research was supported by SuanSunandha Rajabhat University.

\section{References}

Chandhasa, R. (2011). Vetiver: Handicraft Product on the Basis of Sufficiency Economy. Bangkok: Dewitt Press

Chomchalow, N. (2011). Vetiver Research, Development and Applications in Thailand.AU J.T. 14(4): 268-274. Bangkok: International Conference on Vetiver of Thailand.

Covey, S.R. (2009).How The Best leaders build Trust. Chicago: Linkage's Eleventh Annual Best of Organization Development Summit in Chicago. Available: http://archerian.wordpress.com/2009/11/05/steven-covey-on-servant-leadership.

J Booth, D. \&Ardika, A., N. (2003).Vetiver Grass: A Key to Sustainable Development on Bali. ConferenceIndonesia: eastbalipovertyproject.org. https://vetiverindonesia.files.wordpress.com/2012/01/article_pdf.pdf

Janyatam, J., \&Sikka, P. (2012).The Development of Nipa Palm Fiber for Use in Product Design.Academic.Architecture Journals Naresuan, 3(1), 94-104.http://archmis.arch.nu.ac.th/arch_ajnu/journal/article_file/article_2012_39.pdf

Jongchansittho, P. (2014). Northern Thai Style Hairpin: The Local Wisdom of a Hairpin Maker. Institute of Culture and Arts Journal Srinakharinwirot University, 16(1), 1-15. http://www.tci-thaijo.org/index.php/jica/article/view/30521/27110

Laowattanaphong, S., \&Smanchat, S.(2012). Analytical Study of Fibers from Banana Trees in Northern Area to Use in Product Design. Academic and Research Journals Rajamangala University of Technology PhraNakho, 6(1), 266-233. http://dx.doi.org/10.14456/jrmutp.2012.16

Provincial community development office of Phayao.(2009). Availble: http://phayaofocus.com/home/index.php?option=com_content \&task=view\&id=125\&Itemid=48

Soodsang, N. (2016). Straw Rope Furniture Design by Macramé Techniques for Housing Decorations.AsianSocialScience, 12(12),173-180. https://doi.org/10.5539/ass.v12n12p173

Tassanapilom, S. (n.d.) Research Reports of Vetiver Handcraft Production Techniques. Department of Household Industry Promotion: Family Industry Promotion Section, Department of Family and Handicraft Industry Promotion, Department of Industry Promotion

\section{Copyrights}

Copyright for this article is retained by the author(s), with first publication rights granted to the journal.

This is an open-access article distributed under the terms and conditions of the Creative Commons Attribution license (http://creativecommons.org/licenses/by/4.0/). 